\title{
Preliminary results of the Social Impact Research Group of MEDEX: the request database (2000-2002) of two Meteorological Services
}

\author{
J. Amaro' ${ }^{1}$, M. Gayà ${ }^{2}$, M. Aran ${ }^{1}$, and M. C. Llasat ${ }^{3}$ \\ ${ }^{1}$ Meteorological Service of Catalonia, Barcelona, Spain \\ ${ }^{2}$ AEMET, Delegació a les Illes Balears, Palma, Spain \\ ${ }^{3}$ Department of Astronomy and Meteorology, University of Barcelona, Barcelona, Spain
}

Received: 18 June 2010 - Revised: 15 October 2010 - Accepted: 3 November 2010 - Published: 20 December 2010

\begin{abstract}
One of the aims of the MEDEX project is to improve the knowledge of high-impact weather events in the Mediterranean. According to the guidelines of this project, a pilot study was carried out in two regions of Spain (the Balearic Islands and Catalonia) by the Social Impact Research group of MEDEX. The main goal is to suggest some general and suitable criteria about how to analyse requests received in Meteorological Services arising out of the damage caused by weather events. Thus, all the requests received between 2000 and 2002 at the Servei Meteorològic de Catalunya as well as at the Division of AEMET in the Balearic Islands were analysed.

Firstly, the proposed criteria in order to build the database are defined and discussed. Secondly, the temporal distribution of the requests for damage claims is analysed. On average, almost half of them were received during the first month after the event happened. During the first six months, the percentage increases by $90 \%$. Thirdly, various factors are taken into account to determine the impact of specific events on society. It is remarkable that the greatest number of requests is for those episodes with simultaneous heavy rain and strong wind, and finally, those that are linked to high population density.
\end{abstract}

\section{Introduction}

The social impact of meteorological phenomena does not only depend on their magnitude. As various authors have pointed out, the concept of risk includes the probability of hazard, exposure and vulnerability. These factors, in

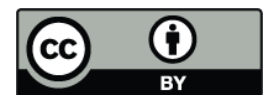

Correspondence to: J. Amaro

(jamaro@meteo.cat) conjunction with psychological, social and economic aspects of the affected population, contribute to perception of natural hazard risk.

In recent decades, studies about the interaction of nature and society and about risk perception have been carried out by several authors (White, 1973; Slovic, 1987; Kasperon et al., 1988). The IPCC report (2001) showed that an increase in climate variability and some extreme events could be projected as a consequence of climate change. As a result, the effects that natural hazards have on society have been of increasing importance among the scientific community. Consequently, in recent years research studies were also conducted in the field of risk concept as a combination of hazard, vulnerability and exposure (Petrova, 2004, 2006; Lastoria et al., 2006; Sterlachini et al., 2007; Llasat et al., 2009a). Moreover, as a part of risk evaluation, psychometric approaches using field studies and questionnaires have been used for risk perception studies (Homan, 2001; Brilly and Polic, 2005; Zhai and Ikeda, 2008; Llasat et al., 2009b) and some relevant perception affecting factors have been integrated into model approaches to quantify risk perception (Plattner et al., 2006).

Nevertheless, increasing societal claim for security and a decreasing level of risk acceptance have involved not only the scientific community. Those responsible for civil protection and the emergency services need contingency plans. Government departments are responsible for applying codes or regulations for building construction and for managing risk assessment correctly. The holistic concept of risk assessment (Bell and Glade, 2004) comprises three equal parts: risk analysis, risk evaluation and risk management. The results from the risk analysis and the risk evaluation allow proper risk management. In this paper, we will focus only on risk analysis using the information available at two Meteorological Services (MS) of Spain.

Published by Copernicus Publications on behalf of the European Geosciences Union. 


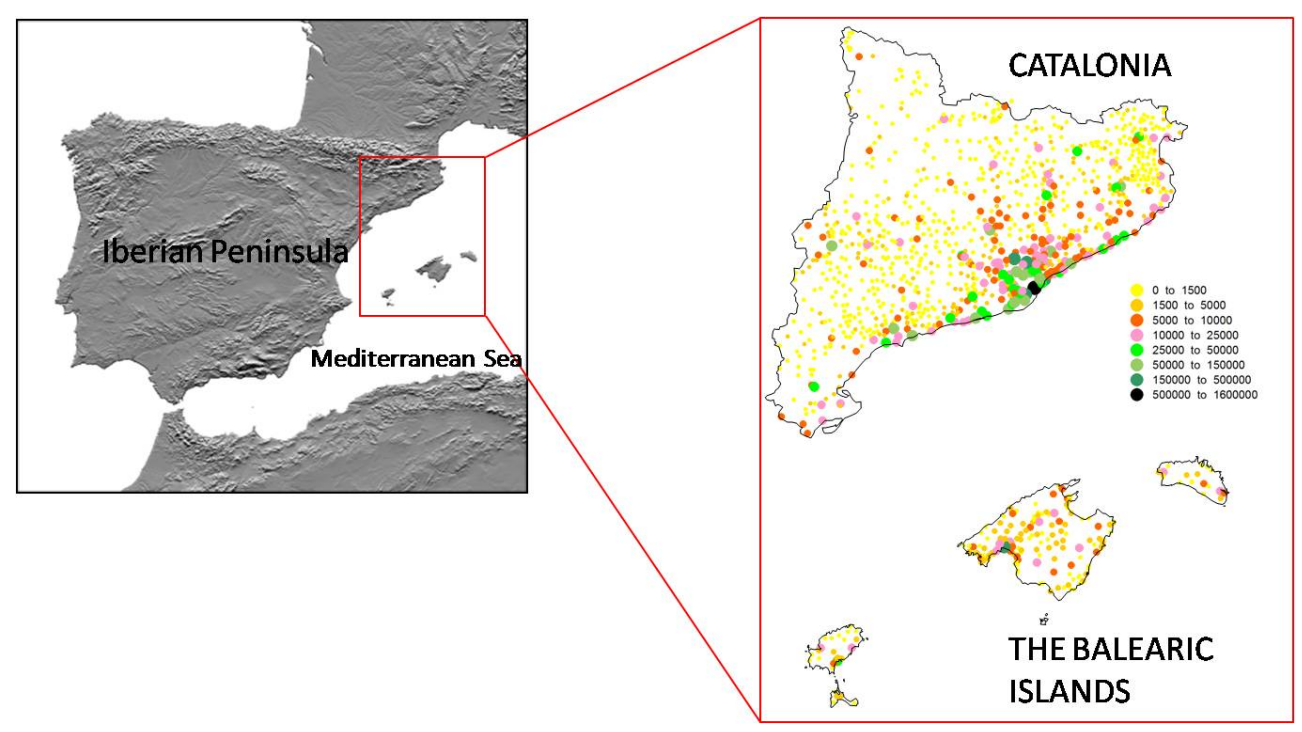

Fig. 1. Geographical situation of Catalonia and the Balearic Islands. On the right, density of population in both regions.

Catalonia, in the northeast part of the Iberian Peninsula, and the Balearic Islands, in the Western Mediterranean Sea (see Fig. 1), are affected by intense cyclones (Genovés et al., 2006; Campins et al., 2006a; Homar et al., 2006, 2007). In Spain, losses resulting from heavy rain and strong wind are subject to compulsory insurance when fixed thresholds of an observed event are exceeded. In consequence, the customer service department of a MS, known as the Public Weather Service (PWS), receives requests from people affected by weather phenomenon and from insurance companies with the purpose of verifying whether or not, according to meteorological conditions, insurance companies are responsible for the corresponding indemnity. Losses deriving from extraordinary risks located in Spain are covered by the Consorcio de Compensación de Seguros (CCS). The CCS is a public entity reporting to the Ministry of Finance and Taxation that defines floods and atypical cyclonic storms as extraordinary meteorological phenomena (pursuant to L 21/1990, of 19 December, according to Directive $88 / 357 /$ CEE; currently derogated by Royal Decree 7/2004, dated 29 October).

The insurance industry is one important source of data on financial losses caused by weather phenomena. In some studies, this information has been used to analyse the social impact of meteorological extremes (Changnon et al., 1997). Also, it has been an interesting tool to study the extreme events evolution and trends on their impacts along the years (Changnon et al., 2000; Barredo, 2009). However, in some countries, such as Spain, there is no a single losses source and the financial data from insurance industry are not always compiled in a public database. Consequently, in this pilot study we will work with damage claim requests received in MS as another proxy indicator, not used before. Thus, the requests for damage compensation received between 2000 and 2002 at the Servei Meteorològic de Catalunya (hereafter SMC) as well as at the division of the Agencia Estatal de Meteorología (hereafter AEMET) in the Balearic Islands were analysed as a way to improve our knowledge of high-impact weather events on the population. This project, led by the Social Impact Research group, is carried out within the framework of the MEDEX project (http: //medex.aemet.uib.es). The main goal of this study is to suggest some general and appropriate criteria to be applied by other countries and periods about how to analyse the requests received at MS. These requests provide a source of information about damage as a consequence of hydrometeorological hazards. It must be noted that CCS information is not included in this study, because its private use.

This paper is structured as follows: first of all, in Sect. 2 (Methodology) the information sources are described. Then, some criteria are proposed in order to build a database. Next, the data processing is briefly described. In Sect. 3 (Analysis of the database) temporal distribution of the requested reports is analysed with the aim of improving knowledge about people's reaction to natural hazards. Various factors are then taken into account to assess their relevance for the impact that specific events have on society. Finally, in Sect. 4 (Conclusions) some remarks and future perspectives are given.

\section{Methodology}

Various policies exist among the MSs in different countries. Furthermore, within a single country, organisations with different economic policies can also coexist. In this pilot 
project, two different organisations in Spain were involved: the division of AEMET in the Balearic Islands (hereafter AEMET-BI) and the SMC. Over the period 2000-2002 policies did not change in either of them. One of the chief aims of this project is to define some criteria to be applied independently of policies, such that it could stand as a guideline to be followed by other MSs.

\subsection{Data available}

\subsubsection{Application forms}

The PWS of AEMET and SMC have application forms in order to homogenise the information received from citizens. Fields included in the application forms are about personal and hydrometeorological hazard information, such as type of meteorological phenomena, location and date; also, there is another field (optional) to explain the reason for the request. Many of these application forms are now sent by mail but for the analysed period (2000-2002) internet was not available in all homes, so most of them were received by fax, post or directly by hand. To archive the request information, some fields of the application forms are entered into a database and they are indexed by their arrival date.

These databases can be considered as one information source on damage caused by natural hazards. Thus, they may prove to be a useful tool for improving knowledge of the events with most consequences for society and they can provide an indicator about the social impact of hazardous meteorological events. However, AEMET and SMC databases were also one of the limitations of this study, because some of the fields included were not specific enough to provide the maximum information. As an example, the municipality where damage occurred is entered in the same field as the type of the phenomena and the requested period.

The number of application forms obtained from the PWS of SMC and AEMET-BI, concerning to the period 20002002 was 10811 and 2187, respectively. Differences in the total number of requests stem from two factors. One is the different economic policy of data, by payment in the case of AEMET and free taxes in the case of SMC. The other one could be that people from distant islands were reluctant to ask for information due to their difficult access to the headquarters located in Palma (Mallorca Island). In future studies for the current period it will be interesting to demonstrate if this drawback had been minimised due to new technologies such as internet.

\subsubsection{Gathering data}

As a part of the MEDEX project there have been considered the events published on its database. The database of MEDEX events is composed of Heavy Rain events (hereafter HR events) and Strong Wind events (hereafter SW events), according to the following criteria:
It is considered a MEDEX event when at least one station exceeded a certain threshold. For HR, the threshold is $60 \mathrm{~mm} 24 \mathrm{~h}^{-1}$ and for SW two different thresholds are set: wind gust greater than $25 \mathrm{~m} \mathrm{~s}^{-1}$ or $33 \mathrm{~m} \mathrm{~s}^{-1}$ for elevated stations.

There was some prior work in checking and validating all the MEDEX events in order to have an accurate database. Although SW events were also considered in the methodology, only HR events will be analysed due to time. This selection is due to the high number of damage incidents, and consequently the strong economic and social impact, that the whole of the phenomena triggered by rainfall have in Spain. According to the Spanish Ministry of the Environment, floods are the natural risk that caused most casualties between 1995 and 2004. The reports published by CCS valued the economic loss for flood damage during the analysed period 2000-2002 at more than four hundred million Euros. In addition, Llasat - Botija et al. (2007) found that flooding was the type of risk that has the greatest coverage in the press, within the area of focus of this study.

\subsection{The Social Impact Research database}

In the attempt to establish a relation between the PWS request database and the MEDEX events, a definition for a SIR event is introduced. Thus, the length of a SIR event was defined without taking into account the synoptic frame and taking account of a bias often produced by the degree of memory of the events (Delitala, 2005; Lastoria et al., 2006). These considerations coincide with the experience in PWS, where the closest contact with people affected by events provides a significant view about public perception. Accordingly, a SIR event has been defined as the period from one day before to one day after the MEDEX event.

A SIR event can be composed of a sequence of MEDEX events if the interval between them is shorter than $24 \mathrm{~h}$; on the other hand, they will be considered as two independent SIR events. This is in accordance with the Gestalt principle of proximity or contiguity, which states that things closer together will be seen as belonging together (Wertheimer, 1923). Subsequently, it can be assumed that events in a short time span can be seen as only one. For the period 2000-2002 a total of 49 SIR events were defined in Catalonia and 37 SIR events for the Balearic Islands.

However, in order to analyse information from the request database it is necessary to apply some criteria in order to build a homogeneous database for each meteorological phenomenon (rain, wind), and minimise differences in policies among MS.

As a first approach, the following criteria were applied to each request:

1. HR and SW events will be considered apart. As a result, independent studies can be carried out for each meteorological phenomenon. 
Table 1. Example of the SIR database for HR events. See text for details.

\begin{tabular}{rrlcccccc}
\hline MEDEXi & MEDEXf & Rain gauge & Max_24h & P1 & P2 & P3 & P4 & SUM \\
\hline 3 Sep 2000 & 4 Sep 2000 & Far de Formentera & $76.0 \mathrm{~mm}$ & 3 & 6 & 6 & 0 & 15 \\
27 Sep 2000 & 27 Sep 2000 & Bunyola Raixa & $90.2 \mathrm{~mm}$ & 4 & 2 & 2 & 0 & 8 \\
12 Oct 2000 & 12 Oct 2000 & Mancor de la Vall & $67.7 \mathrm{~mm}$ & 1 & 3 & 3 & 0 & 7 \\
9 Aug 2002 & 10 Aug 2002 & Sta. Maria Martorelles & $62.5 \mathrm{~mm}$ & 20 & 15 & 44 & 1 & 80 \\
21 Aug 2002 & 26 Aug 2002 & St. Salvador Guardiola & $73.4 \mathrm{~mm}$ & 36 & 9 & 40 & 2 & 87 \\
1 Sep 2002 & 5 Sep 2002 & Ripoll Progrés & $76.5 \mathrm{~mm}$ & 15 & 10 & 32 & 8 & 65 \\
\hline
\end{tabular}

Table 2. Example of the SIR database for SW events. See text for details.

\begin{tabular}{rrllccccc}
\hline MEDEXi & MEDEXf & Wind gauge & Gust & P1 & P2 & P3 & P4 & SUM \\
\hline 16 Feb 2000 & 17 Feb 2000 & Serra d'Alfàbia & $36.4 \mathrm{~m} \mathrm{~s}^{-1}$ & 17 & 11 & 10 & 2 & 40 \\
1 Mar 2000 & 1 Mar 2000 & Serra d'Alfàbia & $40.3 \mathrm{~m} \mathrm{~s}^{-1}$ & 6 & 8 & 8 & 1 & 23 \\
16 Mar 2000 & 16 Mar 2000 & Maó la Mola & $29.7 \mathrm{~m} \mathrm{~s}^{-1}$ & 0 & 4 & 2 & 1 & 7 \\
3 Jan 2003 & 3 Jan 2003 & Font-rubí & $27.2 \mathrm{~m} \mathrm{~s}^{-1}$ & 5 & 6 & 17 & 1 & 29 \\
6 Jan 2003 & 7 Jan 2003 & El Perelló & $41.6 \mathrm{~m} \mathrm{~s}^{-1}$ & 4 & 4 & 20 & 1 & 29 \\
20 Jan 2003 & 4 Feb 2003 & Sant Romà d'Abella & $39.9 \mathrm{~m} \mathrm{~s}^{-1}$ & 184 & 106 & 153 & 19 & 462 \\
\hline
\end{tabular}

2. When the request seeks information for a period in which more than one SIR event took place, it will be counted for each of them. If the request relates to an interval of time longer than one month, it would be not considered. It has to be taken into account that usually citizens are searching over long periods for any event that exceeded insurance thresholds, independently of whether it was the cause of the damage.

3. Only the requests related to damage claims will be considered.

4. Requests relating to damage produced by hail or tornadoes would be included in a HR or SW SIR event respectively. However, requests relating to damage produced by lightning will not be considered, due to a possible correlation with both of them.

5. Only the specific requests for the Balearic Islands or Catalonia are treated by AEMET - BI and SMC, respectively.

Another factor to be considered is the time elapsed between the SIR event and the arrival date of the request. To introduce this information in the SIR database, the request count has been divided into different periods according to their time of arrival. Thus, account has been taken of the requests received during the first ten days after the end of the SIR event (hereafter period P1), the first month (P2), the first six months (P3) and the first year (P4). Requests later than a year from the event were not considered. The SIR database, for HR events, stores for each SIR event the maximum total rainfall value in $24 \mathrm{~h}$, the rain gauge which recorded this maximum and the number of requests associated with the event for each period (Table 1). The SIR database, for SW events, stores for each SIR event the maximum wind speed, the wind gauge which recorded it and the number of requests associated with the event for each period (Table 2).

Finally, to asses this methodology some false events were added randomly in the SIR database. These false events lasted from one to three days and they were days with no rainfall recorded or events in which precipitation amounts were under the MEDEX threshold. After applying the proposed criteria to these false events, a number of requests are associated to them. However, this number of requests is minor compared with the results obtained for the SIR events, as it would be expected. In essence, the second criterion (mentioned above) identifies some requests with events that did not in fact generate damage. Hence, one solution would be not considering requests asking for periods where more than one SIR event took place. The negative aspect of this decision would be a loss of information. So, it seemed more reasonable to retain this rule and to assume an overcount of requests. 


\subsection{Affected population}

With the aim of studying the impact of hazardous weather on the population, it is necessary to add to our database information about the number of inhabitants affected by each SIR event. For this purpose, population cartographies of Catalonia and Balearic Islands were combined with the spatial distribution of the precipitation recorded by automatic weather stations or rain gauges. Thus, to analyse and display all this data the geographic information system (GIS) MiraMon developed by the Centre for Ecological Research and Forestry Applications of the Autonomous University of Barcelona (http://www.creaf.uab.es/MiraMon/) was used.

A first step was to build the precipitation grid data using SURFER software and the kriging interpolation method. Secondly, using MiraMon, precipitation grids were transformed into raster data. Then, the population layer was intersected with the precipitation raster in order to obtain the population affected by rainfall exceeding $60 \mathrm{~mm}$. At this point, the calculations done for Catalonia and the Balearic Islands differ because of the population layer available in each case. For Catalonia a layer where each populated area was represented by a polygon was available, while for the Balearic Islands we had the total population of a town council in each region. The error due to the low resolution in the case of the Balearic Islands can be assumed according to the accuracy of this study.

\section{Analysis of the database}

One of the PWS's mandates is to strengthen interactions with citizens. Therefore, an important part of an MS's image depends on the good running of its PWS. Correct management of human resources ensures working with efficacy and efficiency. Good forecasting of the events that could have more associated requests and knowledge of their distribution over the year can allow PWS to make contingency plans. We have to bear in mind that some episodes can raise the number of requests received at the PWS above the normal figures. Such is the case of the November 2001 episode, in which more than four times the average value of requests was received at both MSs. In these cases it is necessary to increase the resources devoted to the PWS, because response time to citizens cannot also be increased fourfold. Thus, a good estimate can enable immediate actions to prevent population pressure and give a better public service.

Thus, it will be of interest to start with an analysis of the monthly distribution of SIR events and of the associated requests to each one of them. But the SIR events database also contains information about their arrival. So, it can become possible to determine the percentage of requests received for each period. Furthermore, the SIR events with the highest number of associated requests can be obtained, and this will be of useful inferring parameters whose influence could be significant in their impact on population.

\subsection{Monthly distribution}

Climatologically, autumn is the season with the largest precipitation amounts in the Balearic Islands (Font, 1988) and in Catalonia (Llasat and Puigcerver, 1997). Also, it is the season in which the majority of catastrophic floods are concentrated in that area (Barriendos and Martin-Vide, 1998) due to eastern circulation patterns, which are strongly influenced by the Mediterranean dynamics (Romero et al., 1999).

In accordance to the general climatology, autumn is the season with the largest number of MEDEX events in a selected 9-year period, from June 1995 to May 2004 (Campins et al., 2006b, 2007), although in all the other seasons HR events can also occur. Seasonal distribution of SIR events also shows that most of the events take place in autumn (Fig. 2). Despite the seasonal distribution of the SIR events coinciding with the climatology, their monthly distribution is biased by the 3-year period selected for this pilot project compared to the percentage of MEDEX events. Thus, April appears in Catalonia (Fig. 2a) as the second month with largest number of SIR events. In the Balearic Islands (Fig. 2b) July stands out due to rainfalls that occurred in 2002 and exceeded almost all historical records in the Balearic Islands.

Figure 3 shows the monthly distribution of the number of associated requests to each SIR event for the analysed period. It can be seen that in general, the largest number of requests is recorded in September, in the case of Catalonia, and in November in the case of the Balearic Islands. However, for each event and in Catalonia, summer is the season with the largest amount of requests associated with one SIR event, while the number of requests also tends to be higher in months with a lower climatologically frequency of HR event occurrence. Thus, in the case of Catalonia the fact that September has more requests can be explained by the high number of events. This tendency is also found for the Balearic Islands.

Another result that stands out is the highest number of requests in November due to only one SIR event. In November 2001 a storm affected the entire Western Mediterranean area, being one of the most devastating along the Catalan coast and in the Balearic Islands. The event of November 2001 is the 7th in an intensity ranking of cyclones obtained from the climatology based on ERA-40 analyses in terms of circulation for a 45-year period (Genovés et al., 2006) and it also featured strong winds and significant wave heights reaching $6 \mathrm{~m}$ in the wave buoy off the south east of the coast of Catalonia (Sánchez-Arcilla et al., 2008). The combined effect of an SW and a HR event is greater than the sum of their individual effects (synergistic effect). 
(a)

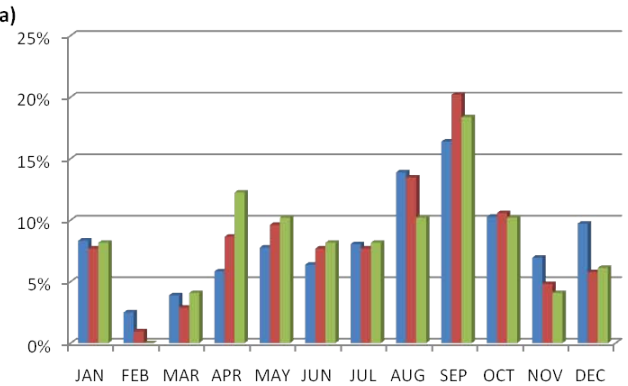

(b)

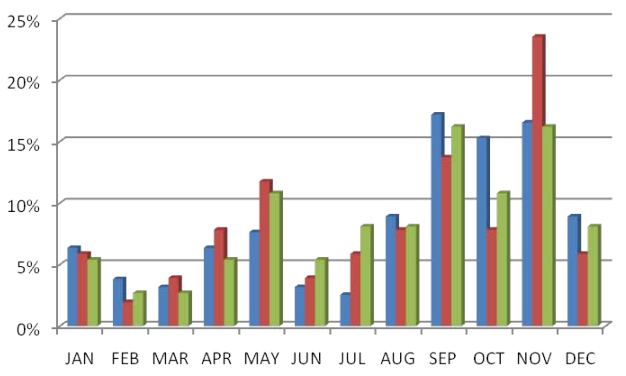

Fig. 2. Monthly distribution (\%) of MEDEX events from June 1995 to May 2004 (blue) and from January 2000 to December 2002 (red), and of SIR events from January 2000 to December 2002 (green) for: (a) Catalonia and (b) the Balearic Islands.
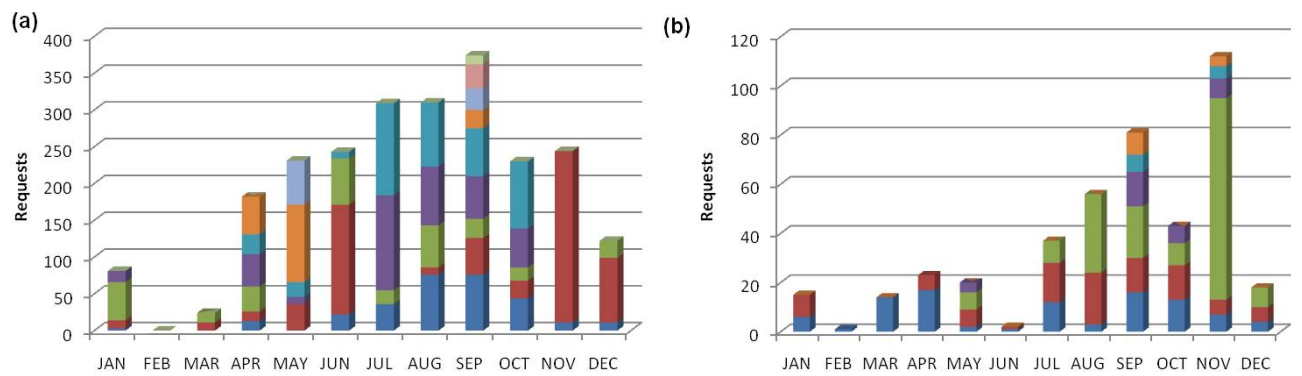

Fig. 3. Monthly distribution of each SIR event requests. Each colour represents the number of requests associated with a SIR event for: (a) Catalonia and (b) the Balearic Islands.

(a)

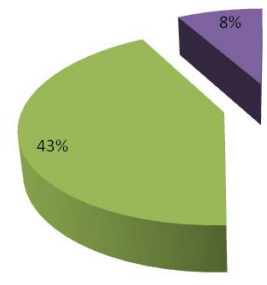

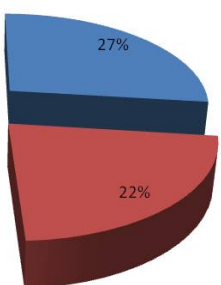

(b)

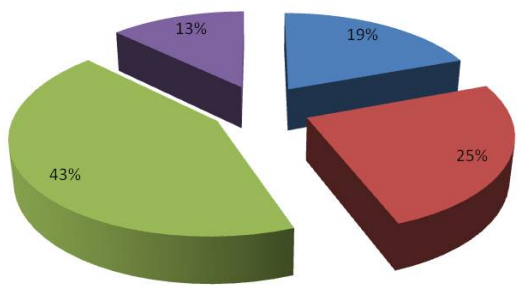

Fig. 4. Percentage of requests received during the first ten days (blue), from the first ten days to the first month (red), from the first month until six months (green) and from the sixth month until the first year (violet): (a) in Catalonia and (b) in the Balearic Islands.

\subsection{Distribution of requests as a function of their arrival period}

Figure 4 shows the percentage of requests received as a function of their arrival period at each MS. On average, almost half of the requests were received during the first month after the event happened. During the first six months, the number increases by $90 \%$. These results support the decision not to consider requests received more than one year of the event, as being a less significant percentage.

Another interesting result is obtained from the analysis of the arrival period and the importance of the SIR event. In this context we can study whether events with different numbers of associated requests also have a different distribution of their arrival (Fig. 5). Although there is no clear tendency between the number of associated requests and their arrival timing, it can be inferred that after six months, the events with a high impact still receive a high percentage of them.
Furthermore, if we analyse the percentage of requests on each arrival period depending on the maximum rainfall (Fig. 6) it can be seen that there is a great heterogeneity for the SIR events with lower rainfall. But for higher amounts we can find a trend towards maintaining a homogeneous percentage of requests in all periods.

\subsection{Factors associated with requests}

As several authors have pointed out (Llasat et al., 2008; Petrucci and Pasqua, 2008; Delitalia, 2005), there's no lineal relationship between precipitation and damage. Phenomena which affect wilderness areas will not induce direct damage on the population and such damage is often unlikely to be reported. In addition, in this study we are focusing on the requests received from citizens, so it seems obvious that results will be highly influenced by the number of inhabitants in each affected area. 
(a)

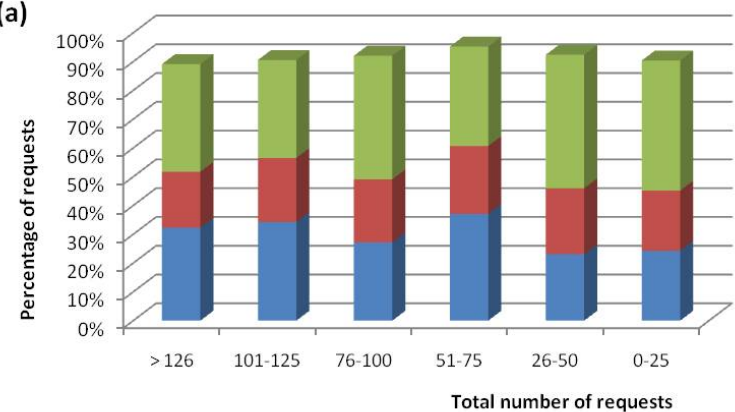

(b)

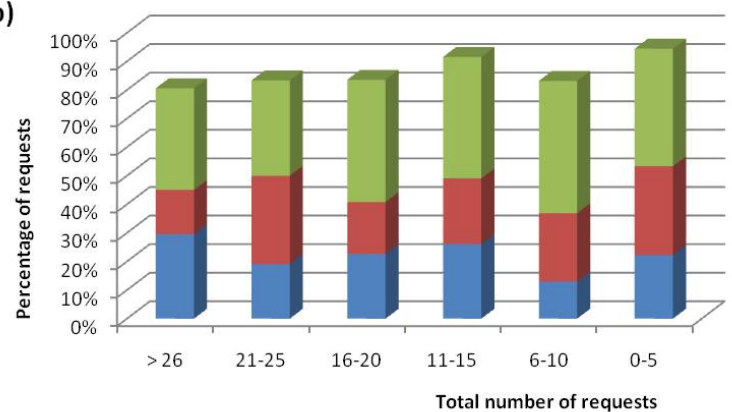

Fig. 5. Bars in different colour show the percentage of requests in the periods discussed in the text grouped into six classes according to the total number of requests for: (a) Catalonia and (b) the Balearic Islands.

(a)

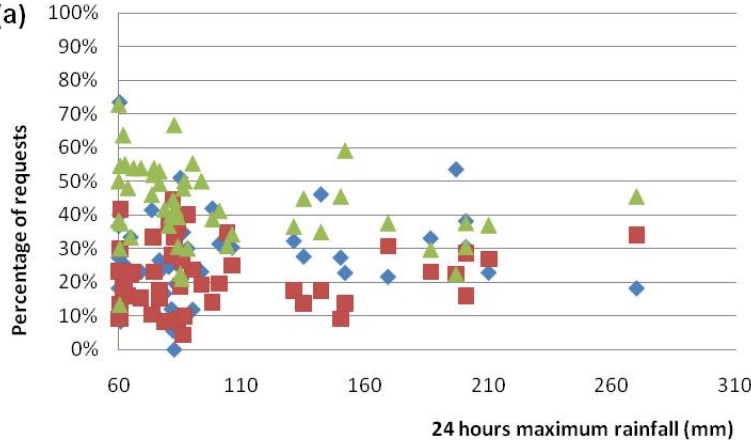

(b)

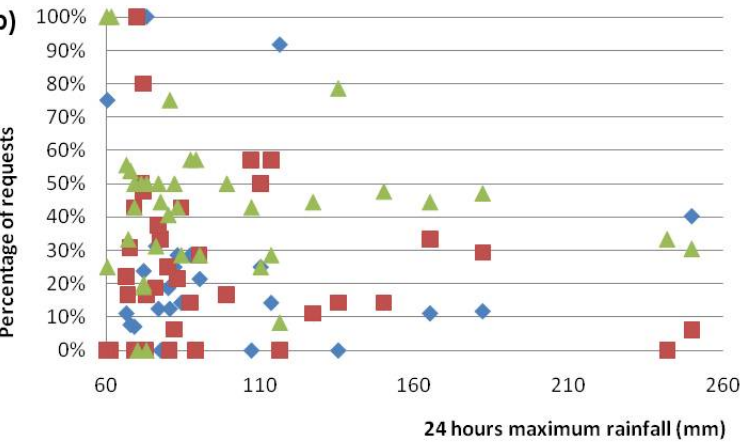

Fig. 6. Interrelation between the percentage of requests in the periods discussed in the text and the maximum rainfall recorded in $24 \mathrm{~h}$ during each SIR event for: (a) Catalonia and (b) the Balearic Islands. The percentage of requests received during the first 10 days is represented by blue diamonds, from 10 days to 1 month by red squares, and from 1 to 6 months by green triangles.

According to the above, and with the aim of controlling it, a new index (PR) has been built (Eq. 1) by multiplying the maximum value for precipitation recorded in $24 \mathrm{~h}$ during the SIR event (Max_24h) with the percentage of the population affected by rainfall exceeding $60 \mathrm{~mm}$ (Po60).

$\mathrm{PR}=$ Max_24h $\cdot$ Po60

The decision to use the maximum precipitation stems from considering that damage can be the effect of the most severe rainfall during the event, as hypothesized by Petrucci and Pasqua (2008). As a result of the application of this new index, we can see that the importance of events with higher rainfall in uninhabited area is minimised (i.e. data in circles in Fig. 7). This new index has markedly improved the adjustment in the case of the Balearic Islands (Fig. 7b). Nevertheless, in the case of Catalonia (Fig. 7a) this new index has not achieved a better correlation.

What is more, there are other factors to be considered in order to explain a little better the impact of an event on population. However, taking into account the difficulty of determining the relevance of each factor, all of them were quantified from 1 to 10 according to different criteria for each of them. The factors that we considered significant in this approach were:
Table 3. Classification of Maximum Rainfall into different levels.

\begin{tabular}{llcl}
\hline$L_{\mathrm{R}}$ & Max_24h & $L_{\mathrm{R}}$ & Max_24h \\
\hline 1 & $0-30 \mathrm{~mm}$ & 6 & $>130-160 \mathrm{~mm}$ \\
2 & $>30-60 \mathrm{~mm}$ & 7 & $>160-190 \mathrm{~mm}$ \\
3 & $>60-90 \mathrm{~mm}$ & 8 & $>190-220 \mathrm{~mm}$ \\
4 & $>90-110 \mathrm{~mm}$ & 9 & $>220-250 \mathrm{~mm}$ \\
5 & $>100-130 \mathrm{~mm}$ & 10 & $>250 \mathrm{~mm}$ \\
\hline
\end{tabular}

1. Maximum precipitation $\left(L_{\mathrm{R}}\right)$. The maximum value of rainfall recorded in $24 \mathrm{~h}$ during the SIR event was classified into ten levels according to the ranges shown in Table 3.

2. Affected population $\left(L_{\mathrm{P}}\right)$. Different levels have been obtained from Eq. (2), where Po60 is the number of people affected by rainfall exceeding $60 \mathrm{~mm}$ and PoT is total population of Catalonia or the Balearic Islands.

$L_{\mathrm{P}}=(\mathrm{Po} 60 / \mathrm{PoT}) \cdot 10$. 

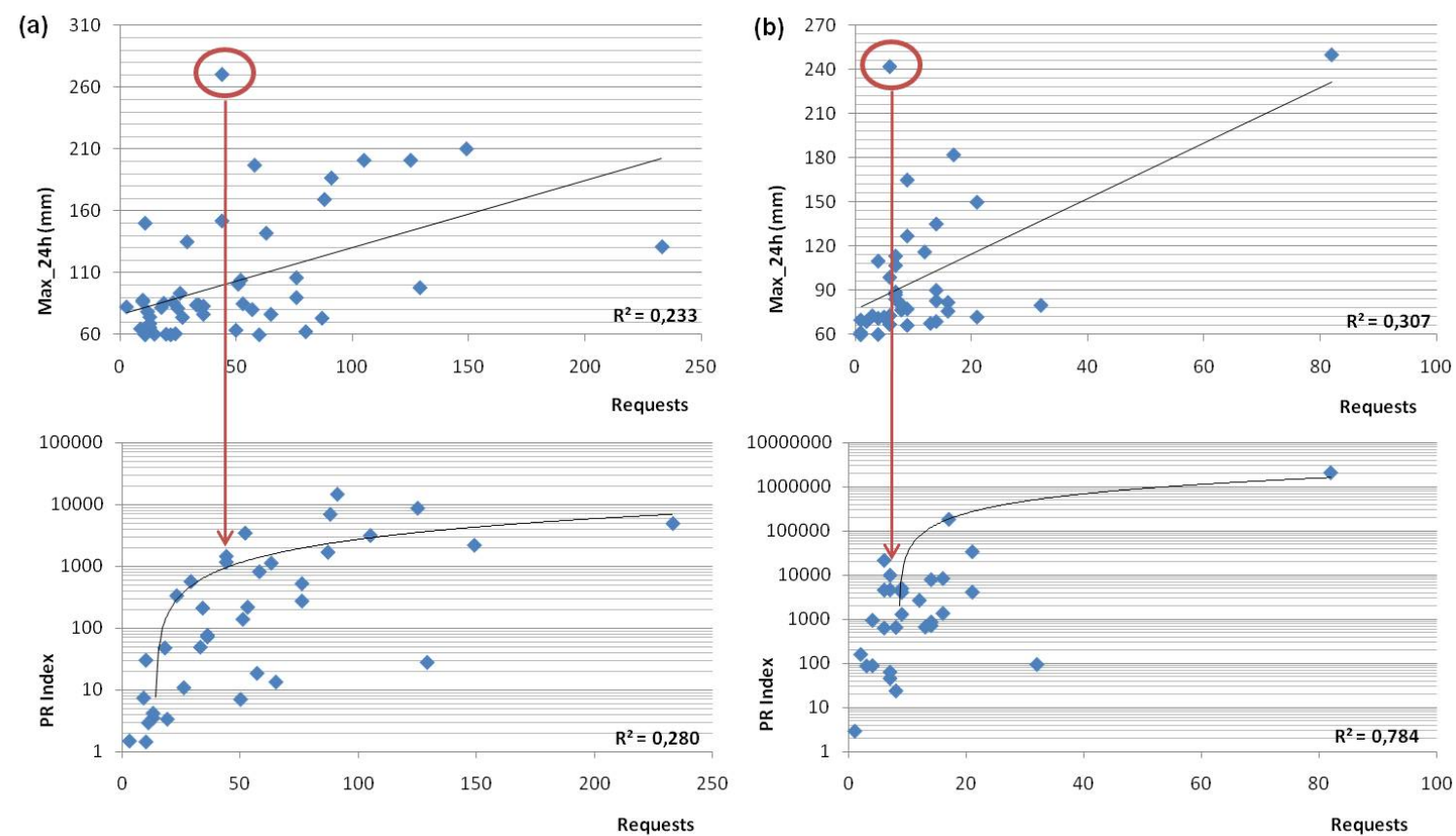

Fig. 7. Interrelation between the number of requests and the maximum rainfall in $24 \mathrm{~h}$ recorded during each SIR event (up) and with the index PR built (down), for: (a) Catalonia and (b) the Balearic Islands.
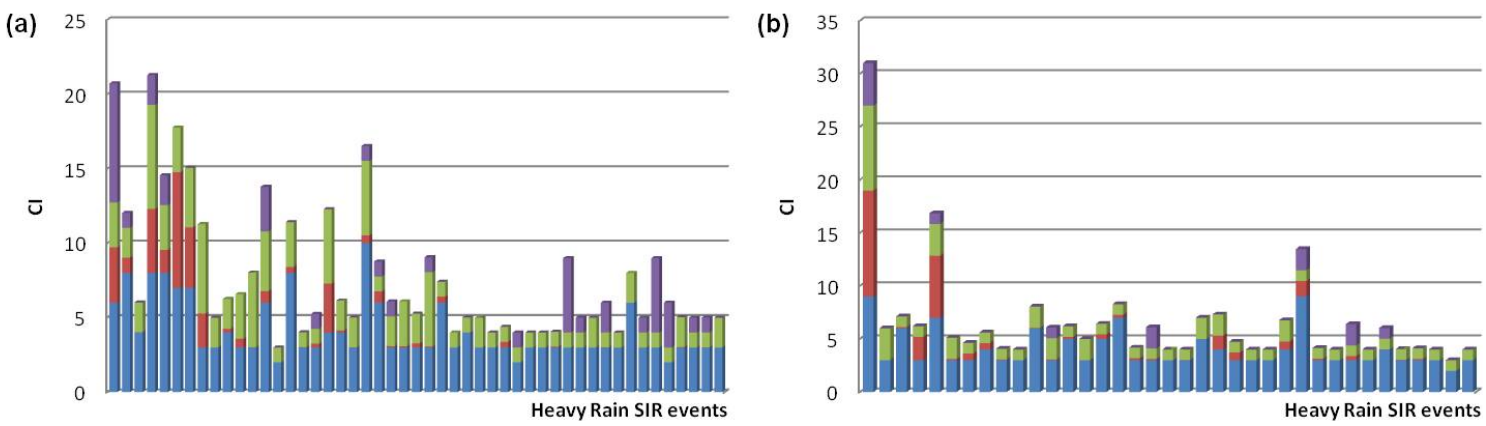

Fig. 8. CI for each SIR event. The factor $L_{\mathrm{R}}$ is shown in blue, $L_{\mathrm{P}}$ in red, $L_{\mathrm{TR}}$ in green and $L_{\mathrm{TW}}$ in violet (see text for details), for (a) Catalonia anb (b) the Balearic Islands. Bars arranged from high (left) to low (right) number of requests.

3. Length of the event $\left(L_{\mathrm{TR}}\right)$ (Pielke and Downton, 2000). Levels are considered as the number of days that the event lasted.

4. Coincidence with a SW event, as well as its persistence $\left(L_{\mathrm{TW}}\right)$. Different levels were considered according to the length of the strong wind event (applying the same criterion as for the previous factor).

As a first attempt to evaluate the total contribution of all these factors, we built a cumulative index (CI) for each SIR event, as a sum of all of them (Eq. 3).
$\mathrm{CI}=L_{\mathrm{R}}+L_{\mathrm{P}}+L_{\mathrm{TR}}+L_{\mathrm{TW}}$

If we represent $\mathrm{CI}$ on Fig. 8, we can see that events with a higher number of requests also had a greater CI. But not all the events can be explained only with the combination of these factors. This is the case of the third SIR event, among those which have received the greatest number of requests at both organisations. These events have a low CI compared with events with a lower number of associated requests. It is interesting to add that these events took place in sparsely populated areas, but with high vulnerability. 


\section{Conclusions}

The analysis of the requests received in a MS can provide an indicator of the social impact of hazardous meteorological events. Thus, one of the major objectives of this study is to unify a methodology to be applied across different organisations and periods. In the light of this purpose, some criteria have been proposed.

In this pilot study, two different organisations with different economic policies on data were involved. A new database was then created and compared with the requests received at both MS for the period 2000-2002. Over that period, policies did not change at either organisation. This database allows an initial approach to determination of the importance and social impact of a meteorological event, not only by the rainfall amount, but also by other factors such as population.

About $90 \%$ of all requests were received within six months after the event, and nearly $50 \%$ arrived during the first month. When the impact increases, a substantial number of requests can arrive after the six months, probably due to delays in the administration of justice.

A new index to evaluate the social impact has been proposed, involving multiplying the maximum precipitation recorded in the event by the percentage of population within a region with more than $60 \mathrm{~mm}$ recorded. This new index provides a good approach to events with higher number of associated requests. Nevertheless, other factors cannot be omitted because of their relevance. Length of the event, vulnerability and intensity also play an important role on the impact of an event. Furthermore, in some events the number of requests is higher if the rain event coincides with a wind event (synergistic effect). Moreover, the intensity of phenomena has not been considered in this study, since data were only available in relation to total rainfall in $24 \mathrm{~h}$; neither was vulnerability taken into account. These factors are key elements in explaining the social impact of events, so a further challenge will be to introduce them.

As a future work it would be of interest to combine these parameters and create a model approach for representing various risk scenarios. It could be an important tool for civil protection departments responsible for drawing up contingency plans.

In addition, the analysis of the results obtained in this paper might help to improve organisation and better management in PWS. A better understanding of the episodes with a greater potential arrival of requests can assist in developing appropriate resource planning to minimise repercussions in a PWS. Thus, it is quite likely to improve the quality and efficiency of the services offered to citizens when the inflow of requests is greater than usual.

Even so, to study the social impact using the requests database, it has to be improved in the future. Accordingly, an automatic request system has to be implemented in a PWS.
An online application form has to allow the monitoring of some important fields such as geographic coordinates, date and time of the damage, if known.

Acknowledgements. This study was carried out within the framework of the WMO Project MEDEX and supported by European Project FLASH (n. 036852). We would like to thank David Demeritt and an anonymous referee for their helpful suggestions and Giorgio Boni for his advice during the editing of the manuscript.

Edited by: G. Boni

Reviewed by: D. Demeritt and another anonymous referee

\section{References}

Barredo, J. I.: Normalised flood losses in Europe: 1970-2006, Nat. Hazards Earth Syst. Sci., 9, 97-104, doi:10.5194/nhess-9-972009, 2009.

Barriendos, M. and Martín-Vide, J.: Secular climatic oscillations as indicated by catastrophic floods in the Spanish Mediterranean coastal area (14th-19th Centuries), Climatic Change, 38,(4), 473-491, 1998.

Bell, R. and Glade, T.: Quantitative risk analysis for landslides Examples from Bldudalur, NW-Iceland, Nat. Hazards Earth Syst. Sci., 4, 117-131, doi:10.5194/nhess-4-117-2004, 2004.

Brilly, M. and Polic, M.: Public perception of flood risks, flood forecasting and mitigation, Nat. Hazards Earth Syst. Sci., 5, 345355, doi:10.5194/nhess-5-345-2005, 2005.

Campins, J., Jansà, A., and Genovés, A.: Three-dimensional structure of Western Mediterranean cyclones, Int. J. Climatol., 26, 323-343, 2006 .

Campins, J., Jansà, A., and Genovés, A.: Heavy rain and strong wind events and cyclones in the Balearics, Adv. Geosci., 7, 7377, doi:10.5194/adgeo-7-73-2006, 2006b.

Campins, J., Aran, M., Genovés, A., and Jansà, A.: High impact weather and cyclones simultaneity in Catalonia, Adv. Geosci., 12, 115-120, doi:10.5194/adgeo-12-115-2007, 2007.

Changnon, S. A., Changnon, D., Fosse, E. R., Hoganson, D., Roth Sr., R. J., and Totsch, J.: Effects of recent weather extremes on the insurance industry: major implications for the atmospheric sciences, B. Am. Meteorol. Soc., 78, 425-435, 1997.

Changnon, S. A., Pielke Jr., R. A., Changnon, D., Sylves, R. T., and Pulwarty, R.: Human factors explain the increased losses from weather and climate extremes, B. Am. Meteorol. Soc., 81, 437442, 2000.

Delitala, A. M. S.: Perception of intense precipitation events by public opinion, Nat. Hazards Earth Syst. Sci., 5, 499-503, doi:10.5194/nhess-5-499-2005, 2005.

Font, I.: Climatología de España y Portugal, Instituto Nacional de Meteorología, Madrid, 1988.

Genovés, A., Campins, J., and Jansà, A.: Intense storms in the Mediterranean: a first description from the ERA-40 perspective, Adv. Geosci., 7, 163-168, doi:10.5194/adgeo-7-163-2006, 2006.

Homan, J.: A culturally sensitive approach to risk? 'Natural' hazard perception in Egypt and the UK, Australian Journal of Emergency Management, 14-18, 2001. 
Homar, V., Jansà, A., Campins, J., and Ramis, C.: Towards a climatology of sensitivities of Mediterranean high impact weather - first approach, Adv. Geosci., 7, 259-267, doi:10.5194/adgeo7-259-2006, 2006.

Homar, V., Jansà, A., Campins, J., Genovés, A., and Ramis, C.: Towards a systematic climatology of sensitivities of Mediterranean high impact weather: a contribution based on intense cyclones, Nat. Hazards Earth Syst. Sci., 7, 445-454, doi:10.5194/nhess-7-445-2007, 2007.

IPPC: Climate Change 2001, Impacts, Adaptation and Vulnerability, Cambridge Univ. Press, 2001.

Kasperon, R. E., Renn, O., Slovic, P., Brown, H. S., Emel, J., Goble, R., Kasperon, J. X., and Ratick. S.: The Social Amplification of Risk: a Conceptual Framework, Risk Anal., 8, 177-187, 1988.

Lastoria, B., Simonetti, M. R., Casaioli, M., Mariani, S., and Monacelli, G.: Socio-economic impacts of major floods in Italy from 1951 to 2003, Adv. Geosci., 7, 223-229, doi:10.5194/adgeo-7-223-2006, 2006.

Llasat, M. C. and Puigcerver, M.: Total rainfall and convective rainfall in Catalonia, Spain, Int. J. Climatol., 17, 1683-1695, 1997.

Llasat, M. C., López, L., Barnolas, M., and Llasat-Botija, M.: Flash-floods in Catalonia: the social perception in a context of changing vulnerability, Adv. Geosci., 17, 63-70, doi:10.5194/adgeo-17-63-2008, 2008.

Llasat, M. C., Llasat-Botija, M., and López, L.: A press database on natural risks and its application in the study of floods in Northeastern Spain, Nat. Hazards Earth Syst. Sci., 9, 2049-2061, doi:10.5194/nhess-9-2049-2009, 2009a.

Llasat, M. C., Llasat-Botija, M., Barnolas, M., López, L., and Altava-Ortiz, V.: An analysis of the evolution of hydrometeorological extremes in newspapers: the case of Catalonia, 1982-2006, Nat. Hazards Earth Syst. Sci., 9, 12011212, doi:10.5194/nhess-9-1201-2009, 2009b.

Llasat-Botija, M., Llasat, M. C., and López, L.: Natural Hazards and the press in the western Mediterranean region, Adv. Geosci., 12, 81-85, doi:10.5194/adgeo-12-81-2007, 2007.

Petrova, E.: Social and economic factors of the natural risk increasing: estimation of the Russian regions, Nat. Hazards Earth Syst. Sci., 4, 243-248, doi:10.5194/nhess-4-243-2004, 2004.
Petrova, E.: Vulnerability of Russian regions to natural risk: experience of quantitative assessment, Nat. Hazards Earth Syst. Sci., 6, 49-54, doi:10.5194/nhess-6-49-2006, 2006.

Petrucci, O. and Pasqua, A. A.: The study of past damaging hydrogeological events for damage susceptibility zonation, Nat. Hazards Earth Syst. Sci., 8, 881-892, doi:10.5194/nhess-8-8812008, 2008.

Pielke, R. A. and Downton, M. W.: Precipitation and Damaging Floods: Trends in the United States, 1932-97, B. Am. Meteorol. Soc., 13, 3625-3637, 2000.

Plattner, Th., Plapp, T., and Hebel, B.: Integrating public risk perception into formal natural hazard risk assessment, Nat. Hazards Earth Syst. Sci., 6, 471-483, doi:10.5194/nhess-6-4712006, 2006.

Romero, R., Ramis, C., and Guijarro, J. A.: Daily rainfall patterns in the Spanish Mediterranean area: an objective classification, Int. J. Climatol., 19, 95-112, 1999.

Sánchez-Arcilla, A., González-Marco, D., and Bolaños, R.: A review of wave climate and prediction along the Spanish Mediterranean coast, Nat. Hazards Earth Syst. Sci., 8, 12171228, doi:10.5194/nhess-8-1217-2008, 2008.

Slovic, P.: Perception of risk, Science, 236, 280-285, 1987.

Sterlacchini, S., Frigerio, S., Giacomelli, P., and Brambilla, M.: Landslide risk analysis: a multi-disciplinary methodological approach, Nat. Hazards Earth Syst. Sci., 7, 657-675, doi:10.5194/nhess-7-657-2007, 2007.

Wertheimer, M.: Laws of Organization in Perceptual Forms, in: A source book of Gestalt psychology, edited and translated by: Ellis, W. D., Routledge \& Kegan Paul, London, 71-88, 1938 (original work published 1923).

White, G.: Natural hazard research, in: Directions in Geography, edited by: Chorley, R., Menthuen, London, 193-216, 1973.

Zhai, G. and Ikeda, S.: Empirical analysis of Japanese flood risk acceptability within multi-risk context, Nat. Hazards Earth Syst. Sci., 8, 1049-1066, doi:10.5194/nhess-8-1049-2008, 2008. 